\title{
BMJ Open Long-term responses to treatment in UK veterans with military-related PTSD: an observational study
}

\author{
Dominic Murphy, ${ }^{1,2}$ Lucy Spencer-Harper, ${ }^{1}$ Carron Carson, ${ }^{1}$ Emily Palmer, ${ }^{1}$ \\ Kate Hill, ${ }^{1}$ Nicola Sorfleet, ${ }^{1}$ Simon Wessely, ${ }^{2}$ Walter Busuttil ${ }^{1}$
}

To cite: Murphy D, SpencerHarper L, Carson C, et al. Long-term responses to treatment in UK veterans with military-related PTSD: an observational study. BMJ Open 2016;6:e011667. doi:10.1136/bmjopen-2016011667

- Prepublication history for this paper is available online To view these files please visit the journal online (http://dx.doi.org/10.1136/ bmjopen-2016-011667)

Received 25 February 2016 Revised 12 May 2016 Accepted 3 June 2016

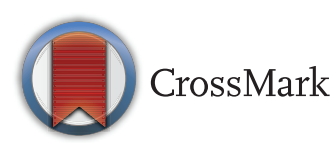

${ }^{1}$ Combat Stress, Leatherhead, UK

${ }^{2}$ King's Centre for Military Health Research, King's College London, London, UK

Correspondence to Dr Dominic Murphy; dominic. murphy@combatstress.org.uk

\section{ABSTRACT}

Objectives: Military-related trauma can be difficult to treat. Evaluating longer term responses to treatment and identifying which individuals may need additional support could inform clinical practice. We assessed 1-year outcomes in UK veterans treated for posttraumatic stress disorder (PTSD).

Design: Within-participant design.

Setting: The intervention was offered by Combat Stress, a mental health charity for veterans in the UK.

Participants: The sample included 401 veterans who completed a standardised 6-week residential treatment. Of these, $268(67 \%)$ were successfully followed up a year after the end of treatment.

Methods: A range of health outcomes were collected pretreatment and repeated at standard intervals posttreatment. The primary outcome was severity of PTSD symptoms, and secondary outcomes included measures of other mental health difficulties (depression, anxiety and anger), problems with alcohol, and social and occupational functioning.

Results: Significant reductions in PTSD severity were observed a year after treatment (PSS-I: $-11.9,95 \% \mathrm{CI}$ -13.1 to -10.7$)$. Reductions in the secondary outcomes were also reported. Higher levels of posttreatment functional impairment $(0.24,95 \% \mathrm{Cl} 0.08$ to $0.41)$ and alcohol problems $(0.18,95 \% \mathrm{Cl} 0.03$ to 0.32 ) were associated with poorer PTSD treatment response at 12 months.

Conclusions: This uncontrolled study suggests the longer term benefits of a structured programme to treat UK veterans with PTSD. Our findings point to the importance of continued support targeted for particular individuals post-treatment to improve longer term outcomes.

\section{INTRODUCTION}

Treatments for veterans with post-traumatic stress disorder (PTSD) seem to be less effective than for matched populations, ${ }^{1-3}$ and veterans with PTSD are at increased risk of high levels of dysfunction and social exclusion. ${ }^{4-6}$ Furthermore, PTSD has been shown to create a higher financial burden to the society than any other mental health conditions in veterans. ${ }^{7}$ Understanding which

\section{Strengths and limitations of this study}

- This study reports treatment response a year after the completion of treatment.

- The study sampled from a national treatment programme offered by the largest provider of interventions for veterans with post-traumatic stress disorder in the UK.

- Of the participants, $67 \%$ were successfully contacted a year after treatment.

- The study did not employ a randomised controlled trial design, so there are limitations about the conclusions that can be drawn.

- Little was known about the treatment experiences of participants prior to them enrolling for treatment.

treatments are effective for this group is a priority.

Following the conflicts in Iraq and Afghanistan, large-scale epidemiological studies explored the health outcomes within the Coalition forces involved. Studies of US military personnel have observed higher rates of PTSD in individuals who have served on deployments to Iraq and Afghanistan. ${ }^{8} 9$ A different picture has emerged in the UK military, with no difference in rates of PTSD observed between those who deployed or not, with rates in both groups of $4 \% .^{10}$ Higher rates of PTSD were, however, observed for groups of UK military personnel who had deployed either into combat roles or were reservists. ${ }^{10}$ Evidence from US military samples suggests an increase in PTSD rates as time since deployment increases, a finding that has not been replicated to date in UK samples where only modest increases have been noted. ${ }^{10}{ }^{11}$ The studies conducted within the UK Armed Forces were last reported in 2010, and little is known about whether the prevalence rates of PTSD have changed over the intervening years. Irrespective of the overall prevalence 
rates of mental illness in UK personnel, the number of referrals from veterans seeking support has increased considerably over time, especially among those who served in Afghanistan. ${ }^{12}$

We have previously reported on treatment response in UK veterans with PTSD attending Combat Stress (CS). CS is a national charity in the UK that provides mental health services to veterans. Outside of the National Health Service (NHS), CS is the largest provider of clinical mental health services to veterans in the UK. Since 2011, CS has been commissioned by the NHS to provide specialist treatment for veterans with military-related PTSD. In an uncontrolled study, attending CS was associated with reduced severity of PTSD symptoms after treatment, and that these gains are maintained 6 months later. ${ }^{13}$ Research from other countries exploring a range of different interventions for PTSD has suggested that as time following treatment increases, there is a reduction in the treatment effect size. ${ }^{14-19}$

In this paper, we now report on longer term outcomes. The outcomes are reported by following up a sample of UK veterans a year after they had received treatment for PTSD. We examined treatment outcome in terms of PTSD symptom severity and a range of other co-morbid mental health difficulties and functional impairment. In addition, we assessed whether health outcomes measured 6 months after the intervention predicted treatment response at 12 months.

\section{METHODS}

\section{Setting}

Participants for this study were recruited from CS. CS has community outreach teams across the UK who offer community-based assessments and low-intensity psychological and occupational supports. In addition, CS has three residential treatment centres where veterans are offered high-intensity interventions. Residential treatment centres employ a multidisciplinary team of healthcare professionals, including psychologists, cognitivebehaviour therapy (CBT) therapists, psychiatric nurses, psychiatrists, occupational therapists, art therapists and support workers.

As standard practice, when individuals were referred to CS, they were offered a mental health assessment by a community psychiatric nurse to ascertain their difficulties and to develop a treatment plan. Individuals were then offered an assessment with a psychiatrist who, where appropriate, made a formal diagnosis of PTSD and provided support to treat mental health difficulties with psychiatric medication. Once veterans had been assessed and given a diagnosis of PTSD, they were referred to a 6-week residential intervention for PTSD that has been named the Intensive Treatment Programme (ITP). The ITP consists of a mixture of individual trauma-focused cognitive-behaviour therapy (TF-CBT) sessions and group sessions. The intervention was standardised and based on a structured manual and ran from 09:00 to 17:00 on weekdays. In a typical day, veterans were offered two 1.5-hour group sessions and supported to practice newly acquired skills between sessions. Over the course of each week, veterans were typically offered three individual therapy sessions. Veterans were assigned to a closed cohort of eight individuals and over the course of the 6 weeks were offered 55 group sessions. Broadly, these groups fell within two categories: psychoeducational groups and symptom management groups. The psycho-education included information on developing a psychological understanding of PTSD, understanding the principles of CBT, providing sleep hygiene information and information about psychiatric medication. Examples of the symptom management groups included behavioural activation for depression, strategies for managing anxiety, using grounding objects to manage dissociation, mindfulness and managing anger. In addition, veterans were offered six weekly art therapy sessions and a further four sessions that were led by an Occupational Therapist, aimed to promote engagement in meaningful activities. In accordance with the National Institute for Health and Care Excellence (NICE) guidance, veterans were offered a minimum of 15 individual TF-CBT sessions (90 min per session) by psychologists or CBT therapists that focused on working on military traumas. Completion of the ITP was defined as being present for a minimum of 5 weeks and having attended at least 15 TF-CBT sessions. Further details of the ITP and the other services offered by CS have been described elsewhere. ${ }^{20}$

\section{Participants}

To improve the representativeness of our sample to the help-seeking veteran population, participants meeting criteria for a range of other mental health and physical health difficulties, in addition to PTSD, were included. However, individuals were excluded if there was evidence of significant neurological impairment that would affect their ability to engage in psychological therapy. This did not exclude participants with mild or moderate traumatic brain injuries. Further exclusion criteria included being actively psychotic, actively dependent on alcohol or actively suicidal, and additional support was provided to the individual before being offered a place on the ITP. For example, this may have included support to engage with a local substance misuse service before being reassessed for their suitability. Individuals were excluded from the study if they had a formal diagnosis of a personality disorder. Inclusion criteria for the ITP included a diagnosis of PTSD, being a veteran (defined in the UK as completing a minimum of 1 day of active service $^{21}$ ) and exposure to two or more military traumas. In addition, for those participants being prescribed psychotropic medication, they had to be stable on their medication and remain on that dose throughout the intervention. Individuals had to have completed treatment and passed the 1-year follow-up point to be included in the data set for the current study. 
Between early 2012 and late 2014, a total of 426 veterans were referred to the ITP. Of these, 401 (94\%) completed treatment. Ten individuals were asked to leave early because of using alcohol during their stay, seven individuals had been deemed unsuitable for therapy by the clinical team, seven individuals had to leave early because of complicated health issues and one individual left because his spouse experienced serious physical health problems. There were no differences between completers and non-completers of the ITP in terms of their pretreatment mental health presentations. ${ }^{13}$ Finally, $352(89 \%)$ of the 401 participants who completed treatment were successfully followed up 6 months later, and similarly to above, we have previously shown no pre- or post-treatment (from a study of those successfully followed up and those lost to follow-up) health differences between participants followed up at 6 months and those lost to follow-up. ${ }^{13}$ Of these 352 participants, $268(76 \%)$ were successfully followed up 12 months after they had completed their treatment. Interpreted by reference to the larger initial sample, $268(67 \%)$ of the 401 participants who completed treatment during the data collection period were successfully followed up 12 months later.

\section{Measures}

At admission, participants were asked to complete a questionnaire providing information on a range of demographic characteristics and baseline health outcomes. These health outcomes were repeated at discharge, and then 6 weeks, 6 months and 12 months later.

\section{Outcome measures}

Our primary health outcome was the cliniciancompleted PTSD Symptom Scale Interview (PSS-I). The PSS-I contains 17 items that adhere to the Diagnostic and Statistical Manual Fourth Edition ${ }^{22}$ diagnostic criteria for PTSD. It can be used to assess for the presence and the severity of PTSD. ${ }^{23}$ In addition, participants completed a range of other outcome measures at each time point. These included the nine-item Patient Health Questionnaire (PHQ-9) to explore symptoms of depression, ${ }^{24}{ }^{25}$ the seven-item Generalised Anxiety Disorders measure (GAD-7), ${ }^{26}$ the five-item Dimensions of Anger Reactions (DAR-5) ${ }^{27}$ the Alcohol Use Disorders Identification Test (AUDIT) ${ }^{28}$ and the Work and Social Adjustment Scale (WSAS) to explored self-reported functional impairment. ${ }^{29}$

\section{Demographic characteristics}

Demographic information was collected on age at admission, sex, educational achievement, employment status and marital status. In addition, information connected to a participant's military career was compiled that included service they had enlisted in (Royal Navy, Army, Royal Air Force), enlistment type (regular or reservist), rank (officer or non-officer), length of service, time since they had left service, areas of deployment and whether they were currently in receipt of a war pension as a result of difficulties related to their military career.

\section{Analysis}

Demographic characteristics and military history were explored. Then, because at 12-month follow-up we were only able to contact 268 of the 352 participants who had responded at 6 months, we explored whether there was evidence of a response health bias at 12 months. Linear regression models were fitted to assess 6-month health outcomes comparing participants who had been successfully followed up or not at 12 months. These models were repeated and adjusted for all of the 6-month health outcomes.

The next stage of the analysis was to explore whether there were changes in health outcome scores over the course of data collection. Random slope non-linear growth models with a fixed coefficient of time squared were fitted to explore the longitudinal health and functional impairment data collected at pretreatment, end of treatment, 6-week, 6-month and 12-month follow-ups. ${ }^{30}$ These analyses were repeated and adjusted for age and employment status. These variables, along with the fixed coefficient of time squared, were found to improve the fit of the models using likelihood ratio tests. The sample used for this analysis was the 401 participants who had completed the ITP. This analysis was repeated but restricted to only the 268 participants who had been followed up 12 months after treatment. The rationale for this was to explore, if there was evidence of a health bias in those lost to follow-up at 12 months, whether this affected the results by comparing between the two models. Six- and 12-month Cohen d's effect sizes were calculated incorporating correlations between pre- and post-treatment PSS-I scores. ${ }^{31} 32$

The final stage of the analysis assessed whether the secondary outcomes we collected at 6-month follow-up were predictors of PTSD outcomes at 12-month follow-up. Univariate linear regression models were fitted between each 6-month outcome and 12-month PSS-I scores. Three adjusted models were then fitted. In Model 1, age and employment status were included, and then Model 2 was further adjusted by adding in the other health outcomes. Model 3 mirrored the previous one but with the addition of 6-month PSS-I scores. Analyses were conducted using Stata V.13 (StataCorp, College Station, Texas, USA).

\section{Ethics}

Ethics approval for this study was granted by the CS ethics committee. Participants provided written consent to take part in treatment and the research.

\section{RESULTS}

The characteristics of the sample are described in table 1. Forty-two per cent of the sample was aged over 
Table 1 Demographic characteristics

\begin{tabular}{|c|c|}
\hline Variable & Number $(\%$ \\
\hline Total completed ITP & 401 \\
\hline \multicolumn{2}{|l|}{ Age group } \\
\hline$<35$ & $100(25)$ \\
\hline $35-44$ & $132(33)$ \\
\hline$>45$ & $169(42)$ \\
\hline \multicolumn{2}{|l|}{ Sex } \\
\hline Male & 394 (98) \\
\hline Female & $7(2)$ \\
\hline \multicolumn{2}{|l|}{ Education } \\
\hline Low (O levels or none) & $346(88)$ \\
\hline High (A levels or above) & 49 (12) \\
\hline \multicolumn{2}{|l|}{ Relationship status } \\
\hline In a relationship & $227(57)$ \\
\hline Single & 171 (43) \\
\hline \multicolumn{2}{|l|}{ Employment status } \\
\hline Working & $146(38)$ \\
\hline Not working & 234 (62) \\
\hline \multicolumn{2}{|l|}{ Receipt of war pension } \\
\hline No & $223(57)$ \\
\hline Yes & $166(43)$ \\
\hline \multicolumn{2}{|l|}{ Service } \\
\hline Royal Navy & $41(10)$ \\
\hline Army & $333(84)$ \\
\hline Royal Air Force & $23(6)$ \\
\hline \multicolumn{2}{|l|}{ Role in military } \\
\hline Non-combat & $89(23)$ \\
\hline Combat & $302(77)$ \\
\hline \multicolumn{2}{|l|}{ Last rank } \\
\hline Officer & $38(10)$ \\
\hline Other ranks & $359(90)$ \\
\hline \multicolumn{2}{|c|}{ Type of discharge from military } \\
\hline Voluntary & $245(63)$ \\
\hline Non-voluntary & $144(37)$ \\
\hline \multicolumn{2}{|l|}{ Years since left the military } \\
\hline $1-9$ & $159(40)$ \\
\hline $10-19$ & $108(27)$ \\
\hline $20-29$ & $89(23)$ \\
\hline $30+$ & $39(10)$ \\
\hline \multicolumn{2}{|c|}{ Number of deployments to conflicts zones } \\
\hline 1 or 2 & $230(59)$ \\
\hline $3+$ & $162(41)$ \\
\hline
\end{tabular}

*Numbers may not add up to 401 because of missing data. ITP, Intensive Treatment Programme.

45 years, $33 \%$ were aged between 44 and 35 years, and $25 \%$ were aged $<35$ years. The mean age was 43.1 years. The sample was predominately male $(98 \%)$, had lower levels of educational achievement $(88 \%)$, had served in the Army (84\%), had been in the lower ranks $(90 \%)$ and served within combat roles $(77 \%)$. Thirty-eight per cent of the sample reported being employed, $57 \%$ in a relationship, $43 \%$ were in receipt of a war pension and $37 \%$ reported that it had not been their decision to leave the military (eg, they had been medically discharged). Sixty per cent of the participants had left the military 10 or more years previously (the mean time period was 14.7 years). The majority of the participants reported that they had deployed to at least one conflict zone during the military service, and $41 \%$ reported that they had deployed to two or more conflicts zones. The most frequently endorsed deployment was to Northern Ireland (55\%), followed by operations to Iraq since 2003 (31\%), Afghanistan since 2001 (22\%), the Balkans $(22 \%)$ and finally the 1991 Gulf War $(15 \%)$.

Table 2 observed whether 6-month health scores differed between participants who were followed up or not at 12 months to assess whether there was a health bias in those lost to follow-up. No significant differences were noted for five of the six health outcomes used in the study. However, participants who were lost to follow-up at 12 months were significantly more likely to have higher scores on the PSS-I at 6 months than those we were able to make contact with. This suggests that severity of PTSD symptoms predicted being lost to 12-month follow-up, though the differences were modest (scores of 23.7 vs 27.6).

The next stage of the analysis was to explore the longitudinal health outcomes from pretreatment to 12 months post-treatment (see table 3). Our primary outcome measure was the PSS-I (PTSD). Significant reductions in the severity of PTSD were observed between pretreatment and 12 months post-treatment. Modest reductions in the severity of the other health outcomes were also observed. In table 2, we reported that participants who were lost to follow-up at this time point were more likely to have modestly higher PSS-I scores at 6 months. Because of this, we were concerned about bias limiting our findings. Model 1 contained all participants available at each time point, and Model 2 was restricted to only those who responded at the final data collection time point. Only marginal differences were observed in the $\beta$-coefficients between these models (eg, PSS-I: -11.7 vs -11.9 ). In an additional analysis, we observed reductions in the severity of PTSD symptoms in $87 \%$ of the participants 6 months after treatment, and this remained roughly consistent at $83 \%$ at the 1-year post-treatment time point. An effect size of 1.04 was found at 6 months and 1.03 at 12 months.

The results in table 4 observed whether health outcomes at 6-month follow-up predicted PTSD severity at 12 months. In the unadjusted regression, and when adjusted for age and employment status, higher scores on all of the health outcome measures at 6 months were associated with worse PSS-I scores at 12 months. Following adjustment for each of the other health outcomes, higher scores on the measures of depression, alcohol problems and functional impairment remained significant predictors of higher PTSD scores at 12 months. When this analysis was repeated, and further adjusted for 6-month PSS-I scores, only alcohol problems and functional impairment remain as significantly associated with poorer PTSD treatment response at 12 months.

\section{DISCUSSION}

In this study, we provided evidence for positive longer term treatment responses in a sample of UK veterans 
Table 2 Health characteristics of those followed up or not at 12 months post-treatment

\begin{tabular}{|c|c|c|c|}
\hline & \multicolumn{2}{|c|}{ Six-month post-treatment scores } & \multirow[b]{2}{*}{$\begin{array}{l}\text { Adjusted } \beta \\
(95 \% \mathrm{Cl})\end{array}$} \\
\hline & $\begin{array}{l}\text { Followed up } \\
\text { Mean (SD) }\end{array}$ & $\begin{array}{l}\text { Not followed up } \\
\text { Mean (SD) }\end{array}$ & \\
\hline PTSD (PSS-I) & $23.7(12.4)$ & $27.6(10.8)$ & $1.03(1.00 \text { to } 1.05)^{*}$ \\
\hline Depression (PHQ-9) & $13.8(7.09)$ & $15.6(6.61)$ & 1.03 (0.99 to 1.07$)$ \\
\hline Generalised anxiety (GAD-7) & $12.2(5.76)$ & $13.4(5.74)$ & $1.02(0.97$ to 1.08$)$ \\
\hline Anger (DAR-5) & 9.44 (6.39) & $9.53(5.40)$ & $1.00(0.95$ to 1.05$)$ \\
\hline Alcohol (AUDIT) & 7.41 (8.29) & 7.56 (8.22) & $1.01(0.97$ to 1.04$)$ \\
\hline Functioning (WSAS) & $21.9(9.89)$ & $24.4(8.86)$ & $1.02(0.99$ to 1.05$)$ \\
\hline
\end{tabular}

Table 3 Twelve-month post-treatment health outcomes

\begin{tabular}{|c|c|c|c|c|c|}
\hline & \multirow[b]{2}{*}{$\begin{array}{l}\text { Admission } \\
\text { score } \\
\text { Mean (SD) }\end{array}$} & \multirow[b]{2}{*}{$\begin{array}{l}\text { 12-Month } \\
\text { score } \\
\text { Mean (SD) }\end{array}$} & \multirow[b]{2}{*}{$\begin{array}{l}\text { Unadjusted } \beta \\
(95 \% \mathrm{Cl})\end{array}$} & \multicolumn{2}{|l|}{ Adjusted $\beta$} \\
\hline & & & & $\begin{array}{l}\text { Model } 1 \\
(95 \% \mathrm{Cl})\end{array}$ & $\begin{array}{l}\text { Model } 2 \\
(95 \% \mathrm{Cl})\end{array}$ \\
\hline PTSD (PSS-I) & $36.5(7.40)$ & $24.9(11.6)$ & $-11.7(-12.6$ to -10.7$)$ & $-11.7(-12.7$ to -10.6$)$ & $-11.9(-13.1$ to -10.7$)$ \\
\hline Depression (PHQ-9) & $17.1(5.18)$ & $15.0(8.45)$ & $-4.21(-4.82$ to -3.60$)$ & $-4.23(-4.86$ to -3.60$)$ & $-4.08(-4.83$ to -3.33$)$ \\
\hline $\begin{array}{l}\text { Generalised anxiety } \\
\text { (GAD-7) }\end{array}$ & $15.6(4.78)$ & $13.0(6.71)$ & $-4.26(-4.82$ to -3.69$)$ & $-4.25(-4.83$ to -3.66$)$ & $-4.32(-5.04$ to -3.59$)$ \\
\hline Anger (DAR-5) & $11.3(5.16)$ & $9.41(5.56)$ & $-2.61(-3.08$ to -2.15$)$ & $-2.57(-3.06$ to -2.09$)$ & $-2.58(-3.17$ to -2.00$)$ \\
\hline Alcohol (AUDIT) & $8.92(8.42)$ & $7.21(8.01)$ & $-1.02(-1.51$ to -0.53$)$ & $-1.07(-1.56$ to -0.57$)$ & $-1.21(-1.77$ to -0.65$)$ \\
\hline Functioning (WSAS) & $25.2(8.24)$ & $22.3(10.3)$ & $-2.87(-3.69$ to -2.04$)$ & $-2.97(-3.81$ to -2.13$)$ & $-2.92(-3.94$ to -1.91$)$ \\
\hline
\end{tabular}

treated for PTSD. The intervention they received was a standardised 6-week residential treatment programme that consisted of a mixture of closed groups and individual TF-CBT sessions. Improvements post-treatment were noted at the end of treatment, and evidence was presented to suggest that these gains were maintained for the majority 12 months later. Modest improvements in our secondary outcomes of co-morbid difficulties such as depression, anxiety, problems with anger, alcohol difficulties and self-reported functional impairment that were maintained 12 months after participants completed treatment were observed. Associations were noted between higher levels of depression or functional impairment post-treatment and worse PTSD treatment outcomes at 12 months.

It is frequently observed in the psychological therapy literature that treatment gains reduce over time. ${ }^{4} 1415171833$ With this in mind, we were encouraged that the 12-month post-treatment response presented in this paper was roughly equivalent to the 6-month post-treatment response for this intervention that have been published previously (PSS-I 6-month $\beta$ -12.9 (95\% CI -14.5 to -11.4$)$ vs 12 -month $\beta-11.7$ (95\% CI -13.1 to -10.7$)$. Furthermore, in the current study, we observed an effect size of 1.03 at 12 months, which was very similar to the effect size at 6 months (1.04), both of which can be interpreted as evidence of large effect sizes. ${ }^{31}$ As there was little difference between these effect sizes, this provides positive support for the longer term benefits of the intervention, and our findings compare favourably in terms of effects sizes with studies of Australian and US veterans treated for PTSD (0.9 and 0.7-0.9, respectively) ( $\mathrm{M}$ Creamer, Auditing Combat Stress's performance: an evaluation of the ITP, 2015, Personal Communication). While we have reported significant reductions in PTSD severity 12 months after completing treatment, the majority of participants' $(63.8 \%)$ scores on the PSS-I indicated that they met criterion for probable PTSD. This rate seems equivalent to a study of Canadian veterans who received treatment for PTSD and were also followed up 12 months later, which reported that even with significant reductions in the severity of presentations, over half of their $(57.8 \%)$ sample still met criteria for probable PTSD. ${ }^{34}$

Previous studies have indicated that symptoms of depression and anxiety are predictors of worse treatment response in veterans with PTSD. ${ }^{33}$ The current study 
Table 4 Relationships between 6-month post-treatment health outcomes and 12-month post-treatment PTSD scores

\begin{tabular}{|c|c|c|c|c|}
\hline & \multirow[b]{2}{*}{ Unadjusted $\beta$ (95\% CI) } & \multicolumn{3}{|l|}{ Adjusted $\beta(95 \% \mathrm{Cl})$} \\
\hline & & Model 1 & Model 2 & Model 3 \\
\hline Depression (PHQ-9) & $0.80(0.62 \text { to } 0.98)^{*}$ & $0.79(0.60 \text { to } 0.98)^{*}$ & $0.35(0.07 \text { to } 0.63)^{\star}$ & $0.15(-0.12$ to 0.41$)$ \\
\hline Generalised anxiety (GAD-7) & $0.95(0.73 \text { to } 1.18)^{*}$ & $0.93(0.70 \text { to } 1.16)^{*}$ & $0.26(-0.10$ to 6.63$)$ & $0.05(-0.40$ to 0.29$)$ \\
\hline Anger (DAR-5) & $0.52(0.30 \text { to } 0.75)^{\star}$ & $0.55(0.32 \text { to } 0.78)^{*}$ & $0.08(-0.33$ to 0.17$)$ & $0.03(-0.38$ to 0.07$)$ \\
\hline Alcohol (AUDIT) & $0.24(0.07 \text { to } 0.42)^{*}$ & $0.26(0.07 \text { to } 0.44)^{*}$ & $0.19(0.04 \text { to } 0.35)^{\star}$ & $0.18(0.03 \text { to } 0.32)^{\star}$ \\
\hline Functioning (WSAS) & $0.60(0.47 \text { to } 0.73)^{*}$ & $0.61(0.47 \text { to } 0.74)^{*}$ & $0.37(0.20 \text { to } 0.54)^{*}$ & $0.24(0.08 \text { to } 0.41)^{*}$ \\
\hline
\end{tabular}

Model 1 is $\beta$ adjusted for age and employment status. Model 2 is additionally adjusted for 6 -month health outcomes listed above. Model 3 , in addition to Model 2 , is adjusted for 6 -month post-treatment PSS-I score.

${ }^{*} \mathrm{p} \leq 0.05$.

AUDIT, Alcohol Use Disorders Identification Test; DAR-5, five-item Dimensions of Anger Reactions; GAD-7, Generalised Anxiety Disorders measure; PSS-I, PTSD Symptom Scale Interview; PTSD, post-traumatic stress disorder; WSAS, Work and Social Adjustment Scale.

examined whether post-treatment factors predicted PTSD outcomes at 1-year follow-up. Mental health co-morbidities did not seem to be significant predictors, while functional impairment and problems with alcohol were. It could be that while there may be remission in PTSD symptoms, this does not equate to global improvements in all areas of veterans lives and further support is needed to tackle alcohol dependency and long-term functional impairment that may have resulted from living with chronic symptoms of PTSD. Overall, the scores on the AUDIT exploring problems with alcohol are lower than may have been expected, compared to populations of UK veterans with mental health difficulties. $^{36} 37$ This may be explained by the criteria that excluded potential participants if they had harmful dependent drinking patterns.

\section{Strengths and weaknesses}

This study profited from using a standard intervention that had been manualised to increase our confidence in fidelity of the treatment received by participants. Furthermore, the intervention had high rates of completion, and we were able to follow up a large proportion of our participants. Where participants were lost to follow-up, we were able to assess data collection at previous time points to explore bias. To improve the representativeness of our sample, they were drawn from consecutive referrals to the ITP. This means that while PTSD was the primary diagnosis for participants, individuals with other co-morbid mental health presentations, dual diagnosis alcohol problems and functional impairment should also have been represented in our sample. For example, the mean pretreatment AUDIT score was 8.92 (95\% CI 8.09-9.76), which indicates that the majority of participants met criteria for hazardous drinking. As such, the sample employed for the current study should be representative of the clinical population of help-seeking veterans with PTSD. However, certain subgroups were not represented. For example, one of the exclusion criteria was having a diagnosis of a personality disorder. In addition, only a minority (2\%) of the sample was women compared to $\sim 10 \%$ in the current UK Armed Forces. ${ }^{10}$
The current study did not employ a randomised controlled trial (RCT) design, and we acknowledge the limitations this entails. As such, caution is needed when interpreting the results presented in the paper because we were unable to use randomisation and a control condition to deal with confounding from unmeasured variables. The rationale for the study design used was that CS had been commissioned to provide a clinical service to support UK veterans with PTSD that was based on existing evidence from Australia, ${ }^{14}$ and we have taken advantage of this opportunity to evaluate the impact of this intervention. A possibility exists that the gains observed within the current study resulted from a natural recovery from PTSD. However, participants for this study reported that they had left the military on average 14.7 years before being offered the ITP. We have used time since leaving the forces as a proxy measure for time since trauma (because exposure to military trauma was an inclusion criterion). As such, this provided evidence against the gains reported being as a result of spontaneous recovery as participants had been living with their symptoms for significant periods of time.

It was noted that participants whose symptoms of PTSD were worse at 6-month follow-up were more likely to be lost to follow-up at 12 months. This could have introduced bias into the results presented in this paper by deflating the mean PSS-I score at 12 months as individuals with higher PSS-I were more likely not to have responded at this time point. To attempt to mitigate this, we conducted two identical analyses to explore 12-month treatment outcomes. The first used the full sample at each time point to include participants who were later lost to follow-up, and the second was restricted to only participants successfully followed up at 12 months. Only modest differences were observed between the $\beta$ coefficient in these two models, which suggests that any bias between those lost to follow-up or not at 12 months did not adversely impact our results.

Our results suggest a statistically significant reduction of 11.7 points on the PSS-I between the pretreatment and 12-month follow-up. This does not necessarily equate to a change in probable PTSD diagnosis as there 
was still a high burden of symptoms being reported by study participants. Using existing cut-offs for the PSS-I would suggest that the mean 12-month post-treatment score would be above the cut-off for meeting probable case criterion. However, these cut-offs have not been validated within this population, which makes interpretation difficult. To address this, we are currently collecting data to validate various measures of PTSD against the CAPS-5 for UK veterans.

No information was available about the psychiatric medication participants were prescribed. However, one of the inclusion criteria for a referral to the ITP was that individuals had to be stable on psychiatric medication. This provides some evidence to suggest that any gains observed resulted from completing the ITP rather than psychiatric medication.

\section{CONCLUSIONS}

Meta-analyses have suggested that veterans have less favourable responses to treatment for PTSD than other groups. ${ }^{1-3}$ Given this, it is encouraging that data presented in this paper suggest the longer term benefits of a 6-week residential treatment for veterans with PTSD. The intervention was delivered within veteran-specific clinics using a combination of psychoeducational and symptom management groups and individual TF-CBT. Our results point to a statistically significant reduction in the burden of PTSD symptoms for the participants in our sample and that these gains were maintained 12 months after treatment. More modest treatment responses were noted for a range of other mental health difficulties, problems with alcohol and functional impairment. Our findings suggest the importance of continuing to support veterans after they have completed treatment to maintain gains. In particular, individuals experiencing problems with alcohol, and where there is evidence of high levels of functional impairment, appear to be groups that could profit from further input. While the results presented in this paper may be cause for cautious optimism, further work is needed to explore the intervention described using an RCT to overcome some of the limitations discussed above.

Contributors DM was the principal investigator for this study, was involved in the design of the study, developed the analytical strategy for the paper, conducted the analyses and wrote the paper. LS-H was involved in the design of the study, data collection and commented extensively on the paper. CC was involved in the design of the study, data collection and commented on the paper. EP was involved in the design of the study and commented on the paper. KH was involved in the design of the study, data collection and commented on the paper. NS was involved in the design of the study and commented on the paper. SW was involved in the design of the study and commented extensively on the paper. WB was the chief investigator for the study, was involved in developing the analytic strategy and commented extensively on the paper.

Funding This research received no specific grant from any funding agency in the public, commercial or not-for-profit sectors.

Competing interests SW is a trustee of CS.
Ethics approval Ethics approval for this study was granted by the CS ethics committee.

Provenance and peer review Not commissioned; externally peer reviewed.

Data sharing statement No additional data are available.

Open Access This is an Open Access article distributed in accordance with the Creative Commons Attribution Non Commercial (CC BY-NC 4.0) license, which permits others to distribute, remix, adapt, build upon this work noncommercially, and license their derivative works on different terms, provided the original work is properly cited and the use is non-commercial. See: http:// creativecommons.org/licenses/by-nc/4.0/

\section{REFERENCES}

1. Bisson Jl, Roberts NP, Andrew M, et al. Psychological therapies for chronic post-traumatic stress disorder (PTSD) in adults. Cochrane Database Syst Rev 2013;(12):CD003388.

2. Kitchiner NJ, Roberts NP, Wilcox D, et al. Systematic review and meta-analysis of psychosocial interventions for veterans of the military. Eur J Psychotraumatol 2012;3. http://dx.doi.org/10.3402/ ejpt.v3i0.19267

3. Bradley R, Greene J, Russ E, et al. A multi-dimensional meta-analysis of psychotherapy for PTSD. Am J Psychiatry 2005;162:214-27.

4. Creamer M, Forbes D, Biddle D, et al. Inpatient versus day hospita treatment for chronic, combat-related posttraumatic stress disorder: a naturalistic comparison. J Nervous Ment Dis 2002;190:183-9.

5. Iversen A, Dyson C, Smith N, et al. 'Goodbye and good luck': the mental health needs and treatment experiences of British ex-service personnel. Br J Psychiatry 2005;186:480-6.

6. Kintzle S, Keeling M, Xintarianos E, et al. Exploring the economic and employment challenges facing US veterans: a qualitative study of volunteers of America service providers and veteran clients. Centre for Innovation and Research on Veterans and Military Families, University of Southern California, School of Social Work, 2015.

7. Currier JM, Holland JM, Drescher KD. Residential treatment for combat-related posttraumatic stress disorder: identifying trajectories of change and predictors of treatment response. PLoS One 2014;9: e101741.

8. Sundin J, Herrell RK, Hoge CW, et al. Mental health outcomes in US and UK military personnel returning from Iraq. Br J Psychiatry 2014;204:200-7.

9. Hoge CW, Auchterlonie JL, Milliken CS. Mental health problems, use of mental health services, and attrition from military service after returning from deployment to Iraq or Afghanistan. JAMA 2006;295:1023-32.

10. Fear NT, Jones M, Murphy D, et al. What are the consequences of deployment to Iraq and Afghanistan on the mental health of the UK armed forces? A cohort study. Lancet 2010;375: 1783-97.

11. Rona RJ, Hooper R, Jones M, et al. The contribution of prior psychological symptoms and combat exposure to post Iraq deployment mental health in the UK military. J Trauma Stress 2009;22:11-19.

12. Murphy D, Weijers B, Palmer E, et al. Exploring patterns in referrals to Combat Stress for UK veterans with mental health difficulties between 1994 and 2014. Int J Emerg Ment Health Hum Resilience 2015;17:652-8.

13. Murphy D, Hodgman G, Carson C, et al. Mental health and functional impairment outcomes following a six week intensive treatment programme for UK military veterans with post-traumatic stress disorder (PTSD): a naturalistic study to explore dropout and health outcomes at follow-up. BMJ Open 2015;5:e007051.

14. Creamer $M$, Morris $P$, Biddle $D$, et al. Treatment outcome in Australian veterans with combat-related posttraumatic stress disorder: a cause for cautious optimism? J Trauma Stress 1999;12:545-58.

15. Forbes D, Lewis V, Parslow R, et al. Naturalistic comparison of models of programmatic interventions for combat-related post-traumatic stress disorder. Aust N Z J Psychiatry 2008;42:1051-9.

16. Monson CM, Schnurr PP, Resick PA, et al. Cognitive processing therapy for veterans with military-related PTSD. J Consult Clin Psychol 2006;74:898-907.

17. Johnson DR, Rosenheck R, Fontana A, et al. Outcome of intensive inpatient treatment for combat-related posttraumatic stress disorder. Am J Psychiatry 1996;153:771-7. 
18. Baum N, Brom D, Pat-Horenczyk R, et al. Transitioning from the battlefield to home: an innovative program for soldiers. J Aggression Maltreat Trauma 2013;22:644-59.

19. Turek PW, Yoder M, Grubaugh A, et al. Prolonged exposure therapy for combat-related posttraumatic stress disorder: an examination of treatment effectiveness for veterans of the wars in Afghanistan and Iraq. J Anxiety Disord 2011;25:397-403.

20. Murphy D. Detailing the clinical pathways at Combat Stress for UK veterans experiencing symptoms of complex post traumatic stress disorder. Healthc Couns Psychother J 2016;14:24-7.

21. Dandeker C, Iversen A, Ross J, et al. What is a veteran? Armed Forces Soc 2006;32:161-77.

22. APA. Quick Reference to the diagnostic criteria from DSM-IV. Washington (DC): American Psychiatric Association, 2005.

23. Foa EB, Riggs D, Dancu C, et al. Reliability and validity of a brief instrument for assessing post-traumatic stress disorder. J Trauma Stress 1993;6:459-73.

24. Kroenke K, Spitzer R. The PHQ-9: a new depression diagnostic and severity measure. Psychiatr Ann 2002;32:509-15.

25. Titov N, Dear BF, McMillan D, et al. Psychometric comparison of the PHQ-9 and BDI-II for measuring response during treatment of depression. Cogn Behav Ther 2011;40:126-36.

26. Swinson RP. The GAD-7 scale was accurate for diagnosing generalised anxiety disorder. Evid Based Med 2006;11:184.

27. Forbes D, Alkemade N, Mitchell D, et al. Utility of the Dimensions of Anger Reactions-5 (DAR-5) scale as a brief anger measure. Depress Anxiety 2014;31:166-73.

28. Babor TF, Higgins-Biddle JC, Saunders JB, et al. AUDIT. The alcohol use disorders identification test. Geneva: Department of
Mental Health and Substance Dependence, World Health Organization, 2001.

29. Mundt JC, Marks IM, Shear MK, et al. The Work and Social Adjustment Scale: a simple measure of impairment in functioning. $\mathrm{Br}$ J Psychiatry 2002;180:461-4.

30. Steele F. Multilevel models for longitudinal data. J R Stat Soc Series A 2008;171:5-19.

31. Cohen J. Statistical power analysis for the behavioral sciences. Hillsdale (NJ): Lawrence Erlbaum Associates, 1988.

32. Morris SB, DeShon RP. Combining effect size estimates in meta-analysis with repeated measures and independent-groups designs. Psychol Methods 2002;7:105-25.

33. Richardson D, Contractor A, Armour C, et al. Predictors of long-term treatment outcome in combat and peacekeeping veterans with military-related PTSD. J Clin Psychiatry 2014;75:1299-305.

34. Richardson JD, Eihai JD, Sareen J. Predictors of treatment response in Canadian combat and peacekeeping veterans with military-related PTSD. J Nerv Ment Dis 2011;199:639-45.

35. Murphy D, Busuttil W. Exploring factors that predict treatment outcomes in UK veterans treated for PTSD. Psychol Res 2015;5:441-51.

36. Iversen $\mathrm{AC}$, van Staden $\mathrm{L}$, Hughes $\mathrm{JH}$, et al. The prevalence of common mental disorders and PTSD in the UK military: using data from a clinical interview-based study. BMC Psychiatry 2009;9:68.

37. Murphy D, Palmer E, Wessely $\mathrm{S}$, et al. Prevalence and associations between traumatic brain injury and mental health difficulties within UK veterans accessing support for mental health difficulties. Psychol Res 2015;11:613-23. 